University of New Orleans

ScholarWorks@UNO

\title{
Assessment of rarity of the blackmouth shiner Notropis melanostomus (Cyprinidae) based on museum and recent survey data
}

Martin O'Connell

University of New Orleans, moconnel@uno.edu

Follow this and additional works at: https://scholarworks.uno.edu/ees_facpubs

Part of the Chemistry Commons

\section{Recommended Citation}

O'Connell, M.T. with A.M. U. O'Connell and J.D. Williams. 2005. Assessment of rarity of the blackmouth shiner Notropis melanostomus (Cyprinidae) based on museum and recent survey data. Southeastern Naturalist 4(2): 246-260

This Article is brought to you for free and open access by the Department of Earth and Environmental Sciences at ScholarWorks@UNO. It has been accepted for inclusion in Earth and Environmental Sciences Faculty Publications by an authorized administrator of ScholarWorks@UNO. For more information, please contact scholarworks@uno.edu. 


\section{Humboldt Field Research Institute}

Assessment of Rarity of the Blackmouth Shiner Notropis melanostomus (Cyprinidae) Based on Museum and Recent Survey Data

Author(s): Martin T. O'Connell, Ann M. Uzee O'Connell, James D. Williams

Source: Southeastern Naturalist, Vol. 4, No. 2 (2005), pp. 247-260

Published by: Humboldt Field Research Institute

Stable URL: http://www.jstor.org/stable/3877961

Accessed: 26/05/2011 13:41

Your use of the JSTOR archive indicates your acceptance of JSTOR's Terms and Conditions of Use, available at http://www.jstor.org/page/info/about/policies/terms.jsp. JSTOR's Terms and Conditions of Use provides, in part, that unless you have obtained prior permission, you may not download an entire issue of a journal or multiple copies of articles, and you may use content in the JSTOR archive only for your personal, non-commercial use.

Please contact the publisher regarding any further use of this work. Publisher contact information may be obtained at http://www.jstor.org/action/showPublisher?publisherCode=hfri.

Each copy of any part of a JSTOR transmission must contain the same copyright notice that appears on the screen or printed page of such transmission.

JSTOR is a not-for-profit service that helps scholars, researchers, and students discover, use, and build upon a wide range of content in a trusted digital archive. We use information technology and tools to increase productivity and facilitate new forms of scholarship. For more information about JSTOR, please contact support@ jstor.org. 


\title{
Assessment of Rarity of the Blackmouth Shiner Notropis melanostomus (Cyprinidae) Based on Museum and Recent Survey Data
}

\author{
Martin T. O’Connell ${ }^{1, *}$, Ann M. Uzee O’Connell ${ }^{1}$, \\ AND JAMES D. WILLIAMS ${ }^{2}$
}

\begin{abstract}
Accurate knowledge of an organism's distribution is necessary for conserving species with small or isolated populations. A perceived rarity may only reflect inadequate sampling effort and suggest the need for more research. We used a recently developed method to evaluate the distribution of a rare fish species, the blackmouth shiner Notropis melanostomus Bortone 1989 (Cyprinidae), which occurs in disjunct populations in Mississippi and Florida. Until 1995, N. melanostomus had been collected from only three localities in Mississippi, but in 1995, eight new localities were discovered. We analyzed museum records of fish collections from Mississippi, Florida, and Alabama to compare sampling effort before and after 1995. Results supported our predictions that 1) pre-1995 data would indicate inadequate sampling effort in Mississippi, 2) additional post-1995 sampling improved confidence in the currently known Mississippi distribution, and 3) there has not been enough sampling to accurately represent the actual distribution of $N$. melanostomus in Florida and across its entire known range. This last prediction was confirmed with the recent (2003) discovery of the first $N$. melanostomus in Alabama.
\end{abstract}

\section{Introduction}

The blackmouth shiner, Notropis melanostomus Bortone 1989 (Fig. 1), is considered to be imperiled globally because of its rarity (Litt et al. 2000). Until 2003, this small fish species had only been collected from three separate eastern Gulf of Mexico drainages: Pascagoula River Drainage, MS; Blackwater River Drainage, FL; and Yellow River Drainage, FL (Fig. 2). To better manage the conservation of $N$. melanostomus, it is essential to determine if this disjunct distribution reflects the actual range of the species or if it is an artifact of incomplete sampling effort. Many factors make sampling for $N$. melanostomus difficult. First, $N$. melanostomus is one of the smallest North American cyprinids, with adults rarely reaching $36 \mathrm{~mm}$ SL (O'Connell et al. 1998, Suttkus and Bailey 1990). This small size can contribute to gear avoidance (e.g., escape through standard seine mesh size) and misidentification in the laboratory. Second, although $N$. melanostomus has been collected by

'Pontchartrain Institute for Environmental Sciences, 349 CERM Building - Research and Technology Park, University of New Orleans, New Orleans, LA 70148. ${ }^{2}$ US Geological Survey, 7920 NW 71 st Street, Gainesville, FL 32653. "Corresponding author-moconnel@uno.edu. 
standard seining methods, the most productive collecting method is to locate schools of the fish from a boat and then collect them with a finemesh dip net (Bortone 1993, O'Connell et al. 1998). Without using this approach, the probability of collecting $N$. melanostomus is significantly reduced. Third, the preferred habitats of $N$. melanostomus are in backwater areas (Florida habitats) or isolated lakes and ephemeral ponds (Mississippi habitats). These are not the typical habitats sampled by those fish biologists and ichthyologists interested in maximizing collection diversity or minimizing personal discomfort. Therefore, these areas may have not received adequate sampling attention by past collectors. Finally, a relatively short life span (no more than two years; Suttkus and Bailey 1990) and an affinity for ephemeral habitats make it difficult to consistently collect $N$. melanostomus at known historic localities over time. For

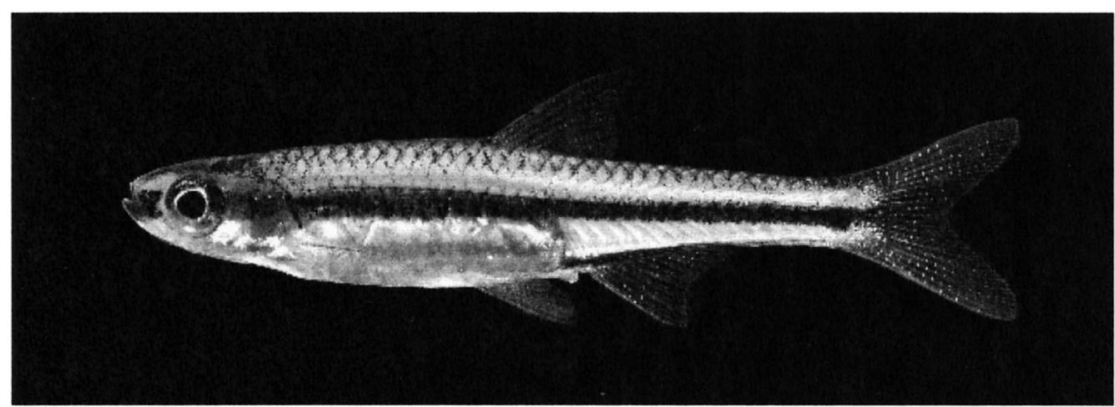

Figure 1. Blackmouth shiner, Notropis melanostomus, $(30 \mathrm{~mm} \mathrm{SL})$ collected on 18 April 2003 from Pond Creek at US Hwy. 90 crossing, southwest of Milton, Santa Rosa County, FL (JDW2003-45). Photograph (C) by Richard T. Bryant.

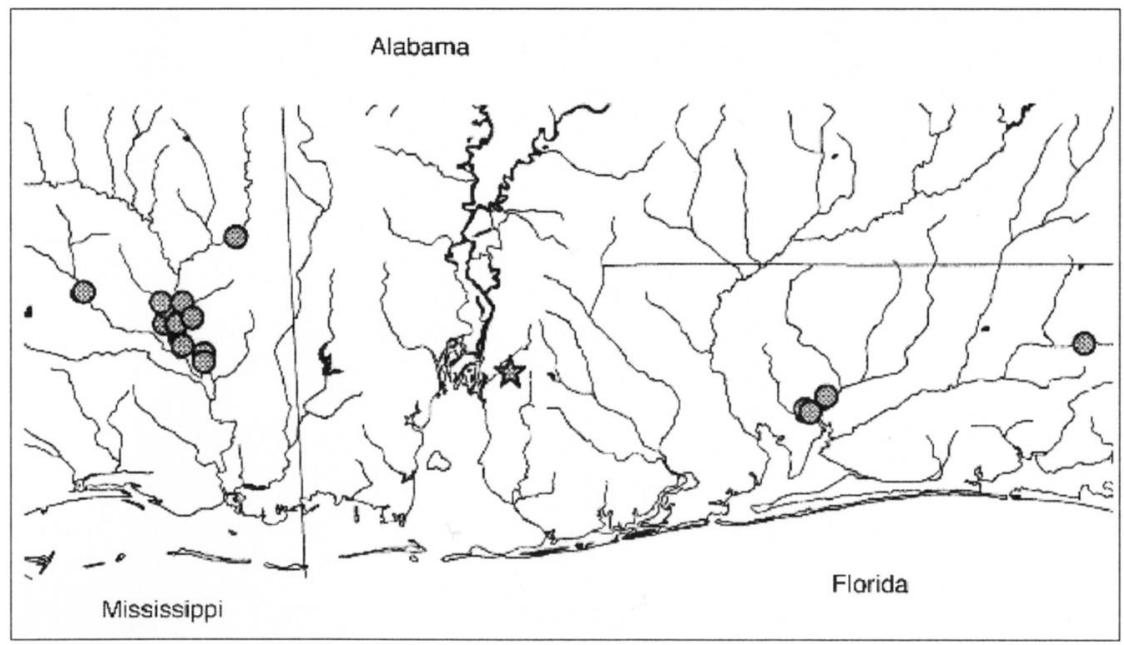

Figure 2. Known distribution of the blackmouth shiner ( $N$. melanostomus) in Mississippi, Alabama, and Florida. Circles indicate localities of collections made prior to 2003. The star indicates the locality of a single collection made on 16 April 2003. 
example, many attempts to re-collect $N$. melanostomus at historic localities have been thwarted because the aquatic habitat no longer exists (e.g., loss of ephemeral pools; O'Connell et al. 1998). If other undiscovered populations of $N$. melanostomus exist, the above factors are likely to have hindered their discovery.

As with other fishes, the known distribution of $N$. melanostomus is a product of compiled museum collection data from various sources. The resulting "dot map" of localities displays the most likely range of the species based on all verified available data. These constructed distributions have been used in various ways to better explain relationships between a species and its environment. For example, museum collection data have been used to determine which environmental variables, climates, and land cover best describe a species' habitat requirements (Anderson and Martínez-Meyer 2004; Edwards et al. 1996; Kadmon and Heller 1998; O'Hara and Poore 2000; Peterson 2001; Peterson and Cahoon 1999; Peterson et al. 2000, 2002a, 2002b; Scott et al. 1996). Analyses of distribution maps have also been used to estimate rates of extinction (Burgman et al. 1995), extirpation (Grogan and Boreman 1998, Lafferty et al. 1999), recolonization (Lafferty et al. 1999), and overall decline (Shaffer et al. 1998, Tuberville et al. 2000) for various species. Unfortunately, under-sampling of species may bias these attempts to relate distributions to ecological data (Colwell and Coddington 1994, Fagan and Kareiva 1997, Heyer et al. 1999, Nelson et al. 1990, Prendergast et al. 1993, Stockwell and Peterson 2002). Therefore, it is essential to determine if enough collection data exist to correctly represent a species' distribution.

We used a spatial analysis method recently developed by Ponder et al. (2001) to test whether the current known distribution of $N$. melanostomus accurately represents the actual range of the species. Our goal was to determine if a lack of sampling effort could explain the perceived rarity of $N$. melanostomus. To do this, we used spatial analysis to quantify distances among collection localities for $N$. melanostomus and co-occurring species to determine the adequacy of background sampling effort for both groups. The analysis measures distances among $N$. melanostomus records, among co-occurring species' records, and between the two groups of records, with smaller distances indicating more adequate sampling effort. If spatial data suggest sufficient overall sampling effort, then we can safely assume $N$. melanostomus is truly rare. However, if there is evidence of significant sampling "gaps" in the data, then more research is needed to properly determine the actual distribution and status of $N$. melanostomus. Therefore, using this spatial analysis method, we tested the following predictions:

1. Prior to a 1995 survey that specifically targeted $N$. melanostomus habitats in Mississippi, there were insufficient data to accurately assess the statewide distribution; 
2. The 1995 survey of Mississippi habitats increased overall confidence in the statewide distribution of $N$. melanostomus; and

3. A comparison of Mississippi data with data from Florida and across the entire range of $N$. melanostomus would indicate that there has not been enough sampling effort to accurately represent the distribution of the species over its entire range (i.e., more undiscovered populations of $N$. melanostomus likely exist).

After we completed these analyses (which included collection data through 2001), N. melanostomus was collected for the first time in Alabama on 16 April 2003 (J.D. Williams, unpubl. data), confirming our prediction that undiscovered populations existed.

\section{Methods}

To determine relative sampling effort for $N$. melanostomus, we compiled two groups of collection locality data. The first group contained data only from collections of $N$. melanostomus. The second group, herein referred to as the background data, contained locality data for six species known to be associated with $N$. melanostomus: golden shiner, Notemigonus crysoleucas (Mitchill 1814); bluenose shiner, Pteronotropis welaka (Evermann and Kendall 1898); eastern mosquitofish, Gambusia holbrooki Girard 1859; brook silverside, Labidesthes sicculus (Cope 1865); largemouth bass, Micropterus salmoides (Lacepede 1802); and bluegill, Lepomis macrochirus Rafinesque 1819 (O'Connell et al. 1998). We chose these particular species to meet a requirement of the original Ponder et al. (2001) study. Background species must be both associated with the target species (i.e., occur in the same habitat) and likely be collected by the same sampling methods used for the target species. Our own experience with field collections of $N$. melanostomus confirms the appropriateness of using these six species as a basis for valid pseudoabsence data. For example, as with most fish sampling for museum specimens, the goal of our sampling efforts always involved collecting a complete representative sample of all species present. Therefore, we can legitimately assume that these six background species are consistently associated with $N$. melanostomus in nature. We addressed a similar issue when we decided to use only records for G. holbrooki and not records for its relative the western mosquitofish, Gambusia affinis (Baird and Girard 1853), though both occur within the distribution of $N$. melanostomus. Both species occur in the western range of $N$. melanostomus (e.g., the Pascagoula Drainage, MS), but only G. holbrooki occurs in natural (i.e., non-introduced) populations in all three states where $N$. melanostomus occurs. By excluding $G$. affinis from the analyses, we avoided using a species that may not meet the requirements of a valid background species.

Both groups of data ( $N$. melanostomus and the background group) represented collections from 16,13, and 12 counties in Mississippi, Alabama, and 
Florida, respectively. Data were requested from the following museums: Mississippi Museum of Natural Science (MMNS, 203 records); Tulane University Museum of Natural History (TU, 5473 records); University of Alabama Ichthyological Collection (UAIC, 526); University of Florida Ichthyology Collection (UF, 1202 records); and University of Southern Mississippi Museum of Ichthyology (USM, 1439 records).

Additionally, FishGopher, an online database of ichthyological collections, was used to obtain data from Cornell University (CU, 28 records), University of Kansas Natural History Museum (KU, 27 records), and Harvard University (MCZ, 5 records). Also, data from a single collection of N. melanostomus were derived from the University of West Florida Fish Collection (UWF, Bortone 1993).

To test our predictions about the adequacy of sampling effort at different times and geographical scales, we divided these collection data into four subsets that, were spatially defined by:

1) the distribution of N. melanostomus in Mississippi prior to 1995 ,

2) the distribution of N. melanostomus in Mississippi after 1995,

3 ) the distribution of N. melanostomus in Florida, and

4) the entire distribution of $N$. melanostomus across all states.

By analyzing the two Mississippi subsets, we could determine changes in sampling effort over time and whether additional collection data improved confidence in the known distribution of $N$. melanostomus in that state. These were compared to the Florida distribution data and the data from the entire distribution of $N$. melanostomus to determine relative sampling effort among the different subsets. We considered any collection of $N$. melanostomus or one of the six associated fish species within the defined regions at a single locality as a "record." The Mississippi subsets prior to and after 1995 included 403 and 497 total records, respectively. The Florida subset included 330 total records, while the subset representing the entire known distribution of $N$. melanostomus had 1025 records. The statistics used to analyze and compare these four subsets of records were generated using Winny v. 1.0 (Kelly 1998), a spatial distribution analysis program (Ponder et al. 2001).

For each subset, two types of statistics were calculated: "within-group statistics" and "between-group statistics" (Ponder et al. 2001). "Withingroup statistics" were calculated separately for the $N$. melanostomus records and for the background records. These described the spatial distributions and relationships between records, and indicated the presence of outliers or clustering (Ponder et al. 2001). For all N. melanostomus records, "within-group statistics" included: maximum and mean separation of each record from every other record, maximum and mean separation of each record from its nearest neighbor, area occupied by the records, density of the records, mean nearest-neighbor separation for a uniform distribution of the same number of records in the same-size area, 
ratio of the actual mean nearest-neighbor separation to that of a uniform distribution (i.e., actual/uniform), and number of records separated by more than the mean nearest-neighbor distance. Adequate sampling for $N$. melanostomus would be indicated by a smaller separation of records and a higher density of records. Conversely, larger distances and lower densities would indicate either that $N$. melanostomus is truly rare or that there is not enough confidence in its reported distribution. The actual/uniform value indicates whether $N$. melanostomus is uniformly distributed (value $\approx 100$ ) or clustered (value $<100$ ). If $N$. melanostomus is rare or inadequately sampled, the actual/uniform value will be large (value $>100$ ). To test for the presence of outliers in $N$. melanostomus records, the number of records that are separated by a distance that is greater than the average nearest-neighbor distance can be examined. If this number is considerably less than half the total number of records, then outlying records exist within the group.

For each subset, the same "within-group statistics" were calculated for background records. All background records that fell within a $50-\mathrm{km}$ buffer of $N$. melanostomus records in each of the four geographical subsets were included in these analyses. As in Ponder et al. (2001), we concentrated on records from within a $50-\mathrm{km}$ buffer of $N$. melanostomus records to standardize sampling, to address the opportunistic nature and localized scale of sampling, and to minimize the non-randomness of species' distributions. For both Mississippi and Florida data subsets, collection information from Alabama that occurred within the $50-\mathrm{km}$ buffer was included in the analyses. For simplicity, the Mississippi subset refers to data from Mississippi and adjoining Alabama, and the Florida subset refers to data from Florida and adjoining Alabama.

"Between-group statistics" included mean between-group distance (and its standard deviation) and minimum between-group distance of each $N$. melanostomus locality from every record in its background group. These statistics describe the distribution of $N$. melanostomus records relative to those of its background group and provide the best indication of confidence in the adequacy of background sampling (Ponder et al. 2001). Again, lower values for these statistics indicate more accurate distributions. To address our predictions, statistics from all four subsets were compared among each other and evaluated based on previously published methods (Ponder et al. 2001). The accuracy of our statistical results was verified through ArcView GIS and the nearest features (nearfeat.avx) extension for ArcView 3.x, v. 3.7 (Jenness 2004).

\section{Results}

\section{Confidence in pre-1995 Mississippi sampling effort}

The low density of $N$. melanostomus records (only three $N$. melanostomus records out of a total of 403 background records, with a 


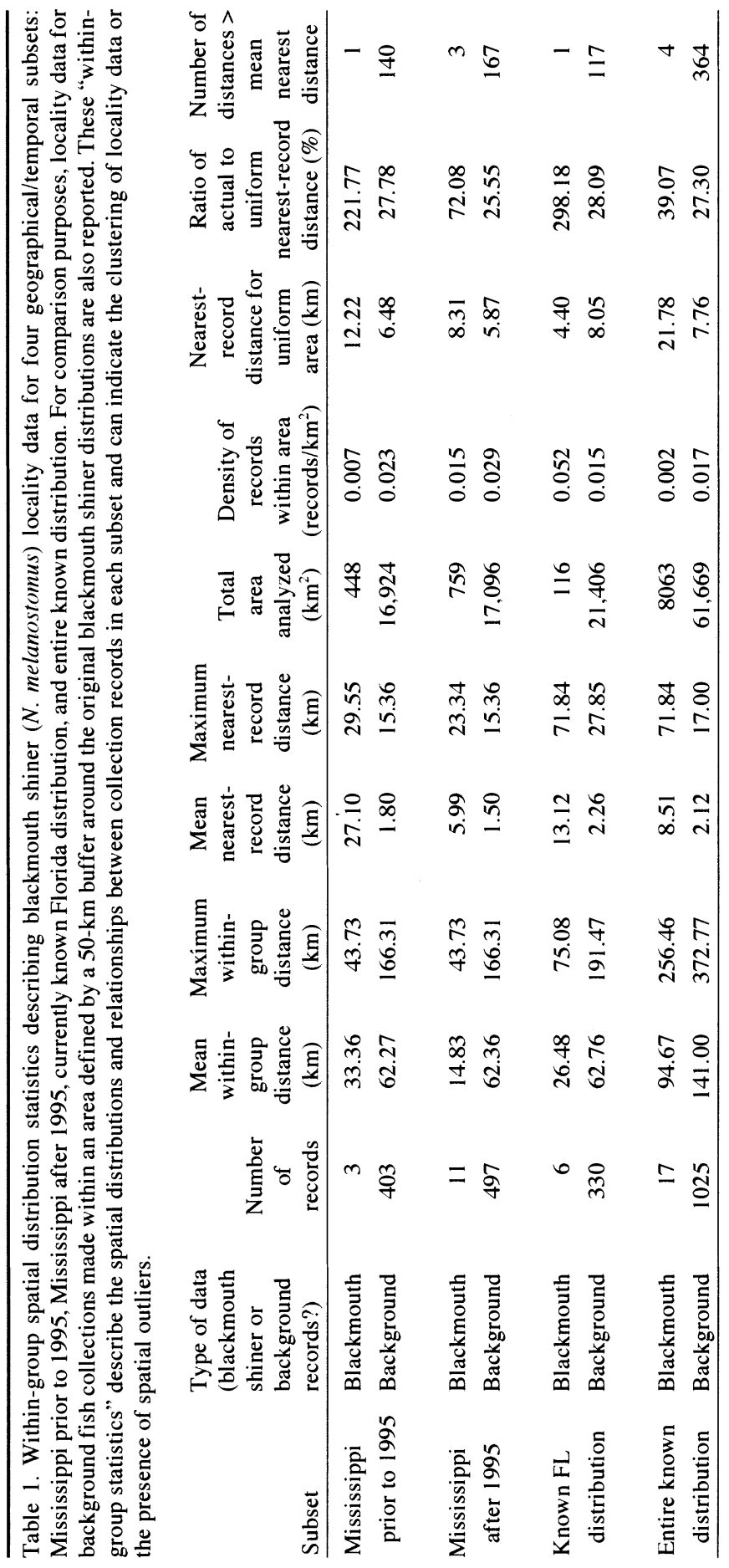


density of 0.007 records $/ \mathrm{km}^{2}$ ) suggests that pre-1995 data are either insufficient to accurately describe the distribution of $N$. melanostomus within Mississippi or that the species is truly rare in the state (Table 1). Also, the high ratio of actual to uniform nearest-record distance (221.77) is indicative of low sample size (Ponder et al. 2001). Although the number of distances greater than the mean nearest-neighbor distance is considerably less than half the total number of records (i.e., one out of three records), this is not an accurate indication of outlying records, again due to low sample size. The similarity between the mean nearest-record distance $(27.10 \mathrm{~km})$ and the maximum nearest-record distance $(29.55 \mathrm{~km})$ better indicates a lack of outlying records.

\section{Increased Mississippi sampling yielded increased confidence in distribution}

Both within-group (Table 1) and between-group (Table 2) statistics indicate that the 1995 survey resulted in increased confidence in the known distribution of $N$. melanostomus in Mississippi. Measures of separation (mean within-group and mean nearest-point distances) decreased markedly from pre-1995 to the current known distribution (Table 1). For example, the mean within-group and mean nearest-point distances decreased by more than half ( 33.36 to $14.83 \mathrm{~km}$ and 27.10 to $5.99 \mathrm{~km}$, respectively). Density of $N$. melanostomus records doubled $\left(0.007\right.$ to 0.015 records $\left./ \mathrm{km}^{2}\right)$ after the 1995 survey, again indicating an increased confidence in its distribution. The ratio of actual to uniform nearest-record distance value of 72.08 also reflects improvement in sampling and shows that the current known distribution in Mississippi is somewhat clustered (Table 1). Within-

Table 2. Between-group spatial distribution statistics showing relationship of blackmouth shiner ( $N$. melanostomus) records to $50-\mathrm{km}$ buffered background records for four geographical subsets: Mississippi prior to 1995, Mississippi after 1995, currently known Florida distribution, and entire known distribution. These between-group statistics describe the distribution of $N$. melanostomus records relative to those of its background group and provide the best indication of confidence in the adequacy of background sampling.

\begin{tabular}{lccccc} 
& $\begin{array}{c}\text { Number of } \\
\text { blackmouth } \\
\text { shiner } \\
\text { records }\end{array}$ & $\begin{array}{c}\text { Number of } \\
\text { background } \\
\text { records }\end{array}$ & $\begin{array}{c}\text { Mean } \\
\text { between- } \\
\text { group } \\
\text { distance } \\
(\mathrm{km})\end{array}$ & $\begin{array}{c}\text { Standard } \\
\text { deviation of } \\
\text { mean between- } \\
\text { group } \\
\text { distance } \\
(\mathrm{km})\end{array}$ & $\begin{array}{c}\text { Minimum } \\
\text { between- } \\
\text { group } \\
\text { distance } \\
(\mathrm{km})\end{array}$ \\
\hline $\begin{array}{l}\text { Subset } \\
\begin{array}{l}\text { Mississippi prior to } \\
1995\end{array}\end{array}$ & 3 & 403 & 54.90 & 24.35 & 0 \\
$\begin{array}{l}\text { Mississippi after } \\
1995\end{array}$ & 11 & 497 & 51.14 & 23.44 & 0 \\
$\begin{array}{l}\text { Known Florida } \\
\text { distribution }\end{array}$ & 6 & 330 & 55.90 & 30.62 & 0 \\
$\begin{array}{l}\text { Entire known } \\
\text { distribution }\end{array}$ & 17 & 1025 & 122.84 & 78.57 & 0 \\
\hline
\end{tabular}


group statistics for background records (mean within-group, maximum within-group, mean nearest-point, and maximum nearest-point distances) showed no change over time. Also, density of background records exhibited minimal change $\left(0.023\right.$ to 0.029 records $\left./ \mathrm{km}^{2}\right)$ from before to after 1995. The records remained clustered, with the ratio of actual to uniform nearest-record distance remaining close to zero in both time periods (27.78 prior to 1995, 25.55 after 1995). For between-group statistics, the decrease in both mean between-group distances and the standard deviation of mean between-group distances from prior to 1995 to post-1995 suggests an improvement in distribution confidence (Table 2). The overall improvement in current Mississippi distribution confidence is evident when the density of background data (a within-group statistic) is plotted against mean between-group separation (a between-group statistic; Fig. 3). In such a plot, confidence in distribution increases from the upper left to the lower right (i.e., increased density of background data and decreased separation between groups; Ponder et al. 2001).

Comparison of sampling effort confidence among subsets representing distributions in Mississippi, Florida, and the entire $N$. melanostomus distribution

Both within-group and between-group statistics indicate that the current known distributions of $N$. melanostomus in Florida and across its entire known range do not accurately reflect the true distribution of this species. For within-group statistics, the lack of similarity between mean

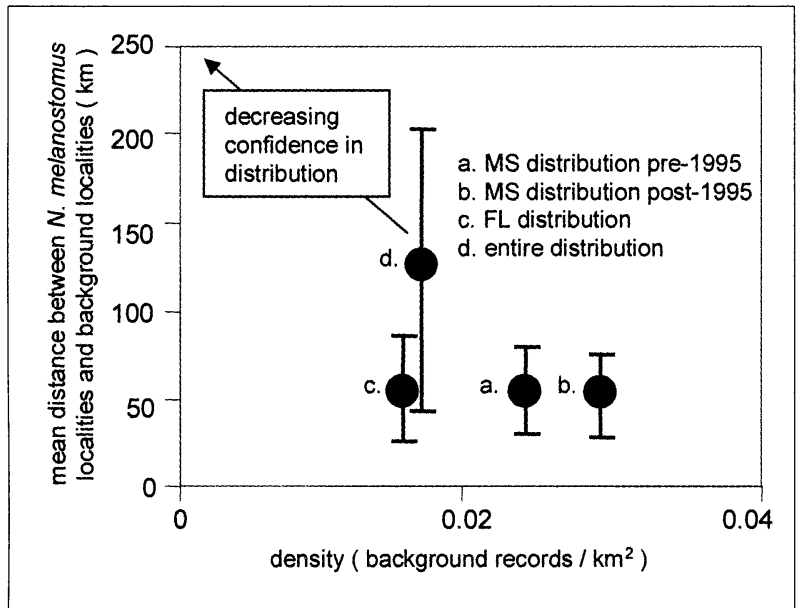

Figure 3. Confidence in four geographical subsets of blackmouth shiner (N. melanostomus) distribution data: a) distribution in Mississippi before 1995, b) distribution in Mississippi after 1995 (after eight new localities were discovered), c) distribution in Florida, and d) entire distribution of the species. Confidence is determined by the density of background records (number of background records $/ \mathrm{km}^{2}$ ) and the mean distance between blackmouth shiner records and their associated background records $(\mathrm{km})$. Error bars represent standard deviation. Within the diagram, lower confidence in distribution data is represented by distributions with lower densities of background records and higher mean distances between blackmouth shiner records and their associated background records. 
nearest-point and maximum nearest-point values suggests the presence of outliers (Ponder et al. 2001). For the known Florida distribution, the mean nearest-point distance was $13.12 \mathrm{~km}$ and the maximum nearest-point was $71.84 \mathrm{~km}$ (Table 1). This trend was repeated for the entire known distribution, with the mean nearest-point being $8.51 \mathrm{~km}$ and the maximum nearestpoint being $71.84 \mathrm{~km}$ (Table 1). For Florida, the high ratio of actual to uniform nearest-record distance (298.18) reflected the low sample size, while that for the entire known distribution (39.07) indicated a high degree of clustering (Table 1). For between-group statistics, the high values for mean and standard deviation of between-group distance statistics (especially relative to Mississippi data) also suggest a lack of confidence in the known distribution (Table 2). The plot of background density versus mean between-group separation shows that confidence in the Florida distribution and the entire species' distribution is markedly less than either of the Mississippi distributions (Fig. 3). The relatively high standard deviation for between-group distances in the entire distribution (78.57) suggests that this subgroup is the least sufficient in describing the actual range of $N$. melanostomus (Fig. 3).

\section{Discussion}

By evaluating museum collection data associated with $N$. melanostomus, we have determined that the current known distribution of this rare species is not adequate to confidently describe its actual range. One purpose of assigning conservation status to a rare species is to determine, through survey work, whether a species is uncommon due to actual rarity or because of incomplete sampling effort. Without an accurate assessment of a rare species' distribution, optimal conservation management cannot be achieved. For example, if resource managers erroneously assume that the current known distribution accurately reflects the range of $N$. melanostomus, other habitats containing undiscovered populations may be destroyed or compromised, further threatening the species. In using the approach developed by Ponder et al. (2001), we have generated three valuable insights regarding the conservation of $N$. melanostomus: 1 ) a lack of sampling effort exists, 2) there are approaches that can be used to improve the confidence in the distribution (e.g., the 1995 Mississippi survey of O'Connell et al. 1998), and 3) there is now a quantifiable way to assess the success of future survey work for this species. Indeed, the recent (2003) discovery of $N$. melanostomus in Alabama confirms that this approach was successful in predicting that unknown populations existed.

Even with this recent finding, the inadequacy of current locality data on $N$. melanostomus demonstrates that more survey work should be among the highest priorities for the conservation of this species. Along with other conservation methods, such as the development of a captive breeding program or the designation of critical habitat, it is critical to 
improve overall confidence in the known distribution of $N$. melanostomus through further sampling efforts. The Ponder et al. (2001) approach provides managers with a cost-effective way to decide whether more sampling is necessary for a species of concern. With access to relevant museum collections' data, appropriate conservation decisions can be made with minimum analysis. The insight generated from analyses of $N$. melanostomus gives a clear direction for future conservation initiatives in Mississippi, Florida, and Alabama.

Our results also suggest how future surveys should be conducted to maximize effectiveness. On both the local scale (within Mississippi, Florida, and now Alabama) and the entire scale of $N$. melanostomus distribution, population localities are mostly clustered and disjunct (Table 1). The improvement in distribution confidence gained through the 1995 survey in Mississippi (O'Connell et al. 1998) was achieved by concentrating sampling effort in the region circumscribed by the three historical localities; among the known sites, an attempt was made to "fill in the gaps." This approach gave surveyors a target area that provided the highest probability of finding undiscovered $N$. melanostomus populations and, therefore, minimized the need for sampling in areas less likely to contain the species. (In retrospect, it was the focusing of sampling among known sites that yielded the successful discovery of the new population in Alabama). We propose a similar method for future survey work in Florida, Alabama, and across the entire known range of $N$. melanostomus. In Florida, the logical area to survey is between the localities in the Blackwater River Drainage and the localities in the Yellow River Drainage (Fig. 1). To "fill in the gaps" for the entire distribution, more survey work should be conducted in the region between the Mississippi and Florida localities in southern Alabama (Fig. 1). Sampling efforts in these areas will maximize the chance of discovering new populations of $N$. melanostomus and minimize the costs compared to surveying larger, possibly less-feasible areas.

Finally, our results provide a standard by which the success of these proposed surveys can be measured. The improvement in distribution confidence for Mississippi generated by the 1995 survey (represented as a movement from the upper-left to the lower-right in Fig. 3) should be the goal of future sampling in Florida and Alabama. With the discovery of a new Alabama population, our hope is to use these new N. melanostomus and background sampling data to recalculate current confidence in the distribution. Although our results show that there is room for improvement with even the current known Mississippi distribution (Table 1), the similarity in standard deviation around mean between-group distances between pre- and post-1995 data (Fig. 3) suggests that at this level of sampling, confidence in distribution has begun to level off. That is, more sampling will likely improve confidence, but with diminishing returns. It should be the goal of future research to improve confidence in the distribution of $N$. melanostomus in Florida, Alabama, and across its entire 
known range to the level represented for the current known Mississippi distribution. Once this is achieved, conservation efforts for this species can be reevaluated to address whether the rarity of $N$. melanostomus is based on its natural distribution or a lack of sampling effort.

\section{Acknowledgments}

The post-1995 study that provided current Mississippi records used in this paper was funded by the Mississippi Department of Wildlife, Fisheries, and Parks. Support for that project was also provided by S. Ross and F. Moore of the University of Southern Mississippi. We thank R. Cashner and J. King of the University of New Orleans for their support of the current study. We thank curators and collections managers (W.T. Slack, MMNS; N. Rios and H. Bart, TU; B. Kuhajda, UAIC; R. Robins and G. Burgess, UF; and S. Ross, USM) who provided us records from their institutions. We especially thank G. Carter for sending us Winny v. 0.1 and his patience in explaining its use through several emails. Sherry Bostick reviewed earlier drafts of the manuscript. This manuscript is Publication No. 2 for the Nekton Research Laboratory, Pontchartrain Institute for Environmental Sciences.

\section{Literature Cited}

Anderson, R.P., and E. Martínez-Meyer. 2004. Modeling species' geographic distributions for preliminary conservation assessments: An implementation with the spiny pocket mice (Heteromys) of Ecuador. Biological Conservation 116:167-179.

Bortone, S.A. 1993. Life history, habitat assessment, and systematics of the blackmouth shiner (Notropis sp.), Blackwater River Drainage. Florida Game and Freshwater Fish Commission, Nongame Wildlife Program final report, Tallahassee, FL. 40 pp.

$\rightarrow$ Burgman, M.A., R.C. Grimson, and S. Ferson. 1995. Inferring threat from scientific collections. Conservation Biology 9:923-928.

Colwell, R.K., and J.A. Coddington. 1994. Estimating terrestrial biodiversity through extrapolation. Philosophical Transactions (Royal Society of London) B 345:101-118.

$\rightarrow$ Edwards, Jr., T.C., E.T. Deshler, D. Foster, and G.G. Moisen. 1996. Adequacy of wildlife habitat relation models for estimating spatial distributions of terrestrial vertebrates. Conservation Biology 10:263-270.

Fagan, W.F., and P.M. Kareiva. 1997. Using compiled species lists to make biodiversity comparisons among regions: A test case using Oregon butterflies. Biological Conservation 80:249-259.

Grogan, C.S., and J. Boreman. 1998. Estimating the probability that historical populations of fish species are extirpated. North American Journal of Fisheries Management 18:522-529.

Heyer, W.R., J. Coddington, W.J. Kress, P. Acevedo, D. Cole, T.L. Erwin, B.J. Meggers, M.G. Pogue, R.W. Thorington, R.P. Vari, M.J. Weitzman, and S.H. Weitzman. 1999. Amazonian biotic data and conservation decisions. Ciencia e Cultura Sao Paulo 51:372-385.

Jenness, J. 2004. Nearest features (nearfeat.avx) extension for ArcView 3.x, v. 3.7. Jenness Enterprises, Flagstaff, AZ. (http://www.jennessent.com/arcview/ nearest_features.htm) 
$\rightarrow$ Kadmon, R., and J. Heller. 1998. Modelling faunal responses to climatic gradients with GIS: Land snails as a case study. Journal of Biogeography 25:527-539.

Kelly, J. 1998. Winny v. 0.1. A Spatial Analysis Program. Heron Parker, Sydney, Australia.

$\rightarrow$ Lafferty, K.D., C.C. Swift, and R.F. Ambrose. 1999. Extirpation and recolonization in a metapopulation of an endangered fish, the tidewater goby. Conservation Biology 13:1447-1453.

Litt, A.R., J.P. McAdoo, J.L. Hardesty, and D.R. Gordon. 2000. Ecology and management of stream aquatic ecosystems on Eglin Air Force Base: Overview, threats, and strategies. Summary of the workshop held at Eglin Air Force Base, November 1-3, 1999. The Nature Conservancy, Niceville, FL. 76 pp.

Nelson, B.W., C.A. Ferreira, M.F. da Silva, and M.L. Kawasaki. 1990. Endemism centres, refugia, and botanical collection density in Brazilian Amazonia. Nature 345:714-716.

O'Connell, M.T., S.T. Ross, J.A. Ewing, and W.T. Slack. 1998. Distribution and habitat affinities of the blackmouth shiner (Notropis melanostomus) in Mississippi, including eight newly discovered localities in the Upper Pascagoula River drainage. Southeastern Fishes Council Proceedings 36:1-6.

$\rightarrow$ O'Hara, T.D., and G.C.B. Poore. 2000. Patterns of distribution for Southern Australian marine echinoderms and decapods. Journal of Biogeography 27:1321-1335.

$\rightarrow$ Peterson, A.T. 2001. Predicting species' geographic distributions based on ecological niche modeling. The Condor 103:599-605.

Peterson, A.T., and K.C. Cohoon. 1999. Sensitivity of distributional prediction algorithms to geographic data completeness. Ecological Modelling 117:159-164.

Peterson, A.T., S.L. Egbert, V. Sanchez-Cordero, and K.P. Price. 2000. Geographic analysis of conservation priorities using distributional modelling and complementarity: Endemic birds and mammals in Veracruz, Mexico. Biological Conservation 93:85-94.

Peterson, A.T., L.G. Ball, and K.C. Cohoon. 2002a. Predicting distributions of Mexican birds using ecological niche modelling methods. Ibis 144:27-32.

Peterson, A.T., D.R.B. Stockwell, and D.A. Kluza. 2002b. Distributional prediction based on ecological niche modeling of primary occurrence data. Pp. 617-623, In J.M. Scott, P.J. Heglund, M.L. Morrison, J.B. Haufler, and M.G. Raphael (Eds.). Predicting Species Occurrences: Issues of Scale and Accuracy. Island Press, Washington, DC. 840 pp.

$\rightarrow$ Ponder, W.F., G.A. Carter, P. Flemons, and R.R. Chapman. 2001. Evaluation of museum collections data for use in a biodiversity assessment. Conservation Biology 15:648-657.

Prendergast, J.R., S.N. Wood, J.H. Lawton, and B.C. Eversham. 1993. Correcting for variation in recording effort in analysis of diversity hotspots. Biodiversity Letters 1:39-53.

Scott, J.M., T.H. Tear, and F.W. Davis. 1996. Gap analysis: A Landscape Approach to Biodiversity Planning. American Society for Photogrammetry and Remote Sensing, Bethesda, MD. 320 pp.

Shaffer, H.B., R.N. Fisher, and C. Davidson. 1998. The role of natural history collections in documenting species declines. Trends in Ecology and Evolution 13:27-30. 
Stockwell, D.R.B., and A.T. Peterson. 2002. Effects of sample size on accuracy of species distribution models. Ecological Modelling 148:1-13.

Suttkus, R.D., and R.M. Bailey. 1990. Characters, relationships, distribution, and biology of Notropis melanostomus, a recently named cyprinid fish from southeastern United States. Occasional Papers of the Museum of Zoology, The University of Michigan 722:1-15.

Tuberville, T.D., J.R. Bodie, J.B. Jensen, L. LaClaire, and J.W. Gibbons. 2000. Apparent decline of the Southern Hog-nosed Snake, Heterodon simus. Journal of the Elisha Mitchell Scientific Society 116:19-40. 